\title{
Endoscopic laser lithotripsy for gallstone large bowel obstruction
}

\author{
Moutaz Alkhusheh, Alfredo Fausto Tonsi \\ Stuart Reiss, E RTC Owen, Kalkata Reddy
}

\begin{abstract}
Background: Colonic Gallstone ileus (CGI) is an uncommon mechanical bowel obstruction caused by intraluminal impaction of one or more gallstones. Gallstones enter the colon though a fistula between the gallbladder and the transverse colon wall. Case Report: We report a case of an 83-year-old lady who presented with symptoms of large bowel obstruction. The Contrast Enhanced Computed Tomography (CECT) of the abdomen showed an obstructing gallstone in the sigmoid colon and extensive diverticulosis. At colonoscopy, a large gallstone was seen impacted in the sigmoid colon. Endoscopic laser lithotripsy under general anesthesia was successful in relieving the obstruction. This procedure
\end{abstract}

Moutaz Alkhusheh ${ }^{1}$, Alfredo Fausto Tonsi ${ }^{1}$, Stuart Reiss $^{2}$, E RTC Owen ${ }^{3}$, Kalkata Reddy ${ }^{4}$

Affiliations: ${ }^{1}$ Senior surgical registrar, Department of Surgery, East Surrey Hospital, Canada Avenue, Redhill, Surrey, $\mathrm{RH} 15 \mathrm{RH}$, United Kingdom; ${ }^{2}$ Surgical trainee, Department of Surgery, East Surrey Hospital, Canada Avenue, Redhill, Surrey, RH1 $5 \mathrm{RH}$, United Kingdom; ${ }^{3}$ Consultant general and colorectal surgery, Department of Surgery, East Surrey Hospital, Canada Avenue, Redhill, Surrey, RH1 5RH, United Kingdom; ${ }^{4}$ Associate specialist in surgery, Department of Surgery, East Surrey Hospital, Canada Avenue, Redhill, Surrey, RH1 5RH, United Kingdom.

Corresponding Author: Dr. Moutaz Alkhusheh, Department of Surgery, East Surrey Hospital, Canada Avenue, Redhill, Surrey, RH1 5RH, United Kingdom;

Phone: 004401737768511;

Email: mbkhusheh@hotmail.com

Received: 25 January 2011

Accepted: 25 March 2011

Published: 30 April 2011 avoided the unfit patient a major surgery. Conclusion: Colonic gallstone ileus is a rare type of large bowel obstruction caused by gallstone impaction in patients with cholecysto-colonic fistula. We describe a case of CGI successfully treated with endoscopic laser lithotripsy. This therapeutic endoscopic approach of impacted colonic gallstone is effective and can be attempted in order to avoid surgery, especially in elderly patients, who are unfit for surgery.

Key words: Endoscopic laser lithotripsy, Colonic gallstone ileus, Endoscopic laser lithotripsy, Contrast enhanced computed tomography

$* * * * * * * * *$

Alkhusheh M, Tonsi AF, Reiss S, Owen E RTC, Reddy K. Endoscopic laser lithotrepsy for gallstone large bowel obstruction. International Journal of Case Reports and Images 2011;2(4):11-14.

$$
* * * * * * * * * \text {. }
$$

doi:10.5348/ijcri-2011-04-28-CR-3

\section{INTRODUCTION}

Despite gallstone ileus accounts for $25 \%$ of non strangulated small bowel obstruction in patients over 65 years of age , colonic gallstone is an uncommon entity [1]. Since Bartolini first described mechanical bowel obstruction secondary to impacted gallstone, different endoscopic options to remove gallstone from the large bowel were attempted. To the best of our knowledge, only one case of colonic gallstone was treated with endoscopic laser lithotripsy [2]. We present a case of 83-year-old lady who presented with 
sigmoid obstruction secondary to gallstone who was successfully treated with one session of endoscopic laser lithotripsy. This technique allows a safe and conservative management of elderly patients with gallstone impaction at the level of the large bowel.

\section{CASE REPORT}

An 83-year-old-lady was admitted to the hospital with 10 day history of abdominal pain and distension, associated with vomiting and constipation. Three weeks earlier, she was admitted with acute diverticulitis which partially settled with a course of antibiotics but soon thereafter patient gradually became generally unwell, persistently vomiting. Her past medical history included hypertension and gallstones, but she never had abdominal surgery in the past. On examination, the vital signs were stable and the abdomen was distended but non-tender and no palpable masses or hernia was detected. The rectal examination was also normal. Blood tests showed: white blood cells $11,000 / \mathrm{mm}^{3}$ (normal 4000$11000 / \mathrm{mm}^{3}$ ), hemoglobin $11.9 \mathrm{gm} / \mathrm{dL}$ (normal 11.5$16 \mathrm{~g} / \mathrm{dL}$ ) but raised urea $13.8 \mathrm{mmol} / \mathrm{L}$ (normal 2.5-6.7 $\mathrm{mmol} / \mathrm{L}$ ) and creatinine $174 \mathrm{mcmol} / \mathrm{L}$ (70-150mc $\mathrm{mol} / \mathrm{L}$ ). The plain abdominal X-ray revealed small and large bowels obstruction upto the level of distal sigmoid colon but no obvious cause of obstruction was seen. The CECT scan of the abdomen revealed small and large bowels obstruction upto to the level of the sigmoid colon where there was a large laminated calcific density, a gallstone, as the cause of obstruction (Figure 1). There was extensive sigmoid diverticulosis, but no evidence of acute diverticulitis. No malignancy was present. Liver, pancreas and kidneys were normal. No free air or fluid was observed.

Patient was admitted to the Intensive Care Unit for fluid resuscitation and renal support. Since the patient was generally unfit for major surgery (i.e. laparotomy and enterotomy to remove the stone), more conservative management in terms of endoscopic removal of the stone was more sensible treatment. At colonoscopy under general anesthesia, the stone was seen impacted proximal to diverticular stricture in distal sigmoid colon (Figure 2). Attempts to remove the stone by an endoscopic basket were unsuccesful. Endoscopic laser lithotrepsy was used to crush the large stone into smaller fragments which were then removed endoscopically, and the obstruction was relieved. The patient improved initially and the abdominal X-Ray next day showed no further bowel obstruction. However, the recovery course was complicated with severe pneumonia after a week, and the patient, unfortunately did not survive.

\section{DISCUSSION}

Large bowel obstruction due to impacted gallstone is uncommon, and to our knowledge only very few case

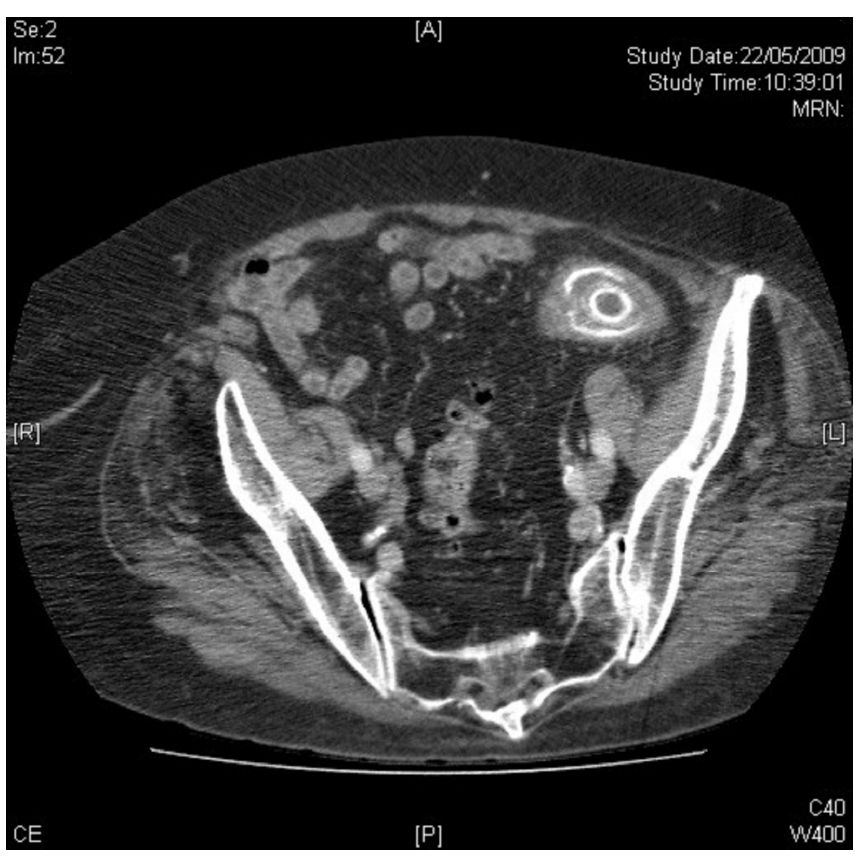

Figure 1: CECT scan shows gallstone obstructing sigmoid colon.

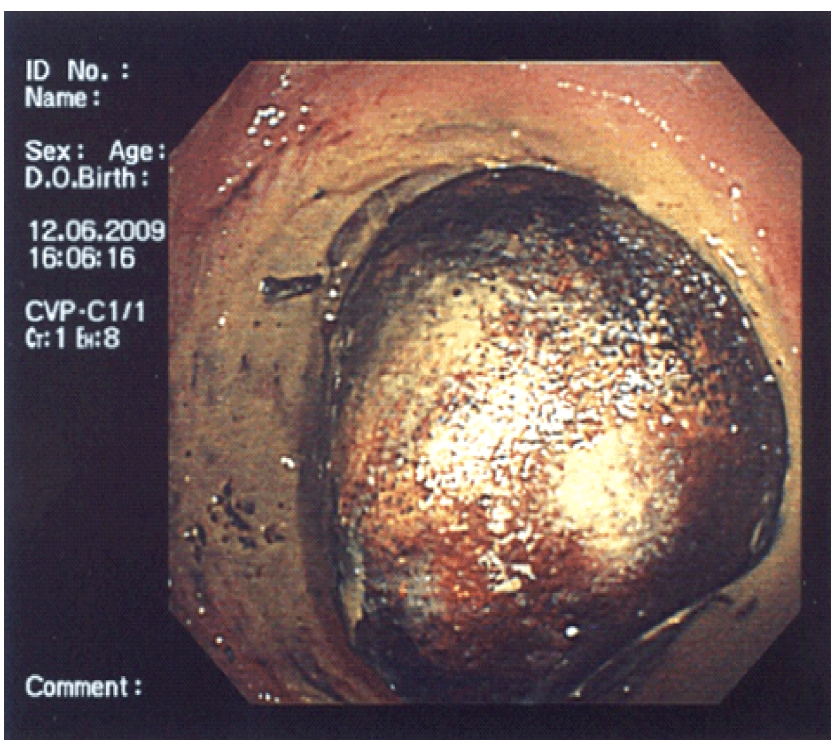

Figure 2: Large gallstone obstructing sigmoid colon at colonoscopy.

reports in literature mentioned this rare complication of gallstone disease. Interestingly, in these few case reports, the treatment widely varied from major open surgery (i.e. laparotomy for closure of the cholecystocolonic fistula and cholecystectomy) which also was done laparoscopically in one case report to less invasive approach like endoscopic removal of the stone if the patient was unfit for such major surgery. The laser lithotripsy for the gallstones in the colon was mentioned only in one case previously. The sigmoid 
colon is the most common site of obstruction [3]. It occurs mostly in the elderly. A colonic fistula is invariably present between gallbladder and hepatic flexure [4].

Colonic gallstones may present with non-specific symptoms (diarrhea, electrolyte imbalance), cholangitis or a bleed from the fistula tract [2]. The classical X-ray description of gallstone ileus is Rigler's triad (ectopic gallstone, partial or complete bowel obstruction and gas in biliary tract) [5]. Pneumobilia is seen in only a third of cases, probably due to occlusion of the cystic duct from the inflamed gall bladder [6-8]. CECT scan has proven to be the most effective imaging technique in these cases $[10,11]$. Treatment options include enterolithotomy, cholecystectomy and fistula closure as a single operation $[6,10,11]$, or colonoscopic removal of the stone, especially in unfit patients [6, 12], who can't tolerate a major surgery which carries a mortality risk upto $10-20 \%$. In our case simple removal of the stone by snare or Dormit Basket was not successful, for this case Laser lithotripsy was the best option which helped to remove the stone endoscopically without the need for major surgery.

\section{CONCLUSION}

Colonic gallstones pose a particular diagnostic challenge and demand a high index of suspicion. The classical Rigler's triad on plain abdominal X-ray may not be present and the CECT scan is the ideal imaging study. The treatment is variable, ideally, enterolithotomy, cholecystectomy and fistula closure as a single operation. However, in unfit or elderly patients this operation carries very significant morbidity and mortality. Therefore, using the endoscopic approach (either simple removal of stone by a basket or, if the stone is large, by laser lithotripsy) is the best option and also very safe and effective treatment.

\section{$* * * * * * * *$}

\section{Author Contributions}

Moutaz Alkhusheh - Substantial contributions to conception and design, Acquisition of data, Analysis and interpretation of data, Drafting the article, Revising it critically for important intellectual content, Final approval of the version to be published

Alfredo Fausto Tonsi - Substantial contributions to conception and design, Acquisition of data, Analysis and interpretation of data, Drafting the article, Final approval of the version to be published

Stuart Reiss - Substantial contributions to conception and design, Acquisition of data, Drafting the article, Final approval of the version to be published

E RTC Owen - Substantial contributions to conception and design of data, Revising the data critically for important intellectual content, Final approval of the version to be published

Kalkata Reddy - Substantial contributions to conception and design, Analysis and interpretation of data, Revising the data critically for important intellectual content, Final approval of the version to be published

\section{Guarantor}

The corresponding author is the guarantor of submission.

\section{Conflict of Interest}

Authors declare no conflict of interest.

\section{Copyright}

(C) Moutaz Alkhusheh et. al. 2011; This article is distributed under the terms of Creative Commons attribution 3.0 License which permits unrestricted use, distribution and reproduction in any means provided the original authors and original publisher are properly credited. (Please see www.ijcasereportsandimages.com /copyright-policy.php for more information.)

\section{REFERENCES}

1. Reisner RM, Cohen JR. Gallstone ileus: A review of 1001 reported cases. Am Surg 1994;60:441-6.

2. Pracki M, Regula J, Pachlewski J, Rupinski M, Cwikla M, Butruk E. Sigmoid laser lithotripsy for gallstone ileus. Folia GastroenterolHepatol 2006;4(1):30-32.

3. Anagnostopoulos GK, Sakorafas G, Kolettis T, Kotsifopoulos N, Kassaras G. A case of gallstone ileus with an unusual impaction site and spontaneous evacuation. J Postgrad Med 2004; 50:55-6.

4. Goldberg RI, Phillips RS, Barkin JS. Spontaneous cholecystocolonic fistula treated by endoscopic sphincterotomy.GastrointestEndosc 1988;34:55-56.

5. Rigler Et Al. Gallstone obstruction: pathogenesis and roentgen manifestation. The journal of the American medical association, Chicago 1941;117:1753-1759.

6. Anagnostopoulos GK, Sakorafas G, Kolettis T, Kotsifopoulos N, Kassaras G. A case of gallstone ileus with an unusual impaction site and spontaneous evacuation. J Postgrad Med 2004;50:55-56.

7. Bose SM, Sastry RA. Agenesis of gallbladder with choledocho-colonic 110 fistula. Am J Gastroenterol 1983;78:34-35.

8. Lassandro F, Gagliardi N, Scuderi M, Pinto A, Gatta G, Mazzeo R. Gallstone ileus analysis of radiological findings in 27 patients.Eur J Radiol 2004;50:23-29.

9. Reimann AJ, Yeh BM, Breiman RS, Joe BN, Qayyum A, Coakley FV. Atypical cases of gallstone ileus evaluated with multidetector computed tomography. J Comput Assist Tomogr 2004;28:523-527.

10. Tan YM, Wong WK, Ooi LL. A comparison of two surgical strategies for the emergency treatment of gallstone ileus. Singapore Med J 2004;45:69-72. 
11. Pavlidis TE, Atmatzidis KS, Papaziogas BT, Papaziogas TB. Management of gallstone ileus. J HepatobiliaryPancreatSurg 2003;10:299-302.

12. Shenoy VN, Limbekar S, Long PB, Bashar AA. Relief of small bowel obstruction following colonoscopy in a case of gallstone ileus. $\mathrm{J}$ ClinGastroenterol 2000;30:326-328. 